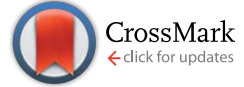

Cite this: RSC Adv., 2015, 5, 12974

Received 16th September 2014 Accepted 12th January 2015

DOI: 10.1039/c4ra10563j

www.rsc.org/advances

\title{
Annealing-induced periodic patterns in solution grown polymer single crystals $\uparrow$
}

\author{
Bin Zhang, ${ }^{\text {abc }}$ Jingbo Chen, ${ }^{c}$ Hui Zhang, ${ }^{a}$ Moritz C. Baier, ${ }^{d}$ Stefan Mecking, ${ }^{d}$ \\ Renate Reiter, ${ }^{\text {af }}$ Rolf Mülhaupt ${ }^{\text {ef }}$ and Günter Reiter ${ }^{\star a f}$
}

\begin{abstract}
Applying a slow annealing procedure, we have transformed geometrically simple, faceted polymer single crystals into periodically branched crystals. Interestingly, the period of the branches increased logarithmically with annealing time and depended on crystallization temperature in a similar fashion as the thickness of the lamellar crystal. We tentatively relate the periodic pattern to meta-stable states, differing in crystalline order and thus melting temperature. The degree of meta-stability and its variance depend on lamellar thickness but can also change with the degree of molecular order, causing differences in melting behaviour. Our results propose that periodic variations in thermal stability within a polymer single crystal can be made visible by annealing.
\end{abstract}

\section{Introduction}

Polymer crystals usually grow under conditions far away from thermodynamic equilibrium, ${ }^{\mathbf{1 - 5}}$ resulting in lamellar crystals of highly folded chain-like molecules. ${ }^{6,7}$ These crystals may exhibit many different, often complex, morphologies. ${ }^{8-11}$ However, in particular in solutions, for many decades polymer crystals with a simple faceted morphology have also been frequently observed. ${ }^{12-15}$ At the corresponding comparatively fast growth rates, ${ }^{\mathbf{1 6}-18}$ polymers cannot equilibrate and meta-stable states of folded polymers are the rule. Consequently, although of simple shape, faceted polymer crystals should consist of polymers differing in degree of molecular order. ${ }^{19-21}$ According to the Gibbs-Thomson relation, ${ }^{22}$ the melting temperature depends on the size of the crystal or the size of the domain of molecules of equal degree of order. Smaller or less ordered regions melt at lower temperatures than larger or better ordered ones. ${ }^{23-27}$ Thus, when annealing faceted crystals at temperatures below the nominal melting temperature, ${ }^{\mathbf{2 8 , 2 9}}$ one may anticipate observing morphological changes which may provide

${ }^{a}$ Institute of Physics, University of Freiburg, 79104 Freiburg, Germany. E-mail: guenter. reiter@physik.uni-freiburg.de

${ }^{b}$ Hermann Staudinger Graduate School, University of Freiburg, 79104 Freiburg, Germany

'School of Materials Science \& Engineering, Zhengzhou University, Zhengzhou 450002, People's Republic of China

${ }^{d}$ Chair of Chemical Materials Science, Department of Chemistry, University of Konstanz, 78464 Konstanz, Germany

Institute of Macromolecular Chemistry, University of Freiburg, 79104 Freiburg, Germany

${ }^{f}$ Freiburg Materials Research Centre, University of Freiburg, 79104 Freiburg, Germany $\dagger$ Electronic supplementary information (ESI) available. See DOI: $10.1039 / \mathrm{c} 4 \mathrm{ra} 10563 \mathrm{j}$ information on the spatial distribution of less ordered regions within faceted crystals and, possibly, on how the faceted crystals were grown.

Annealing-induced morphological changes in polymer single crystals at temperatures well below the nominal melting point have been observed previously. ${ }^{\mathbf{6}, 30-33}$ Local molecular reorganization processes were identified as the central mechanism which allowed to partially remove chain folds with increasing annealing time or annealing temperature. ${ }^{31,34,35}$ As a consequence, the mean lamellar thickness increased, leading to enhanced thermal stability. ${ }^{36,37}$ Pioneering microscopy works ${ }^{38-42}$ on individual single crystals have demonstrated that, as a mere consequence of mass conservation, such annealing induced local thickening ${ }^{43}$ is accompanied by the formation of a "Swiss cheese" morphology or "saw-tooth" patterns. ${ }^{\mathbf{4 4 - 4 7}}$ Such spatially varying changes in morphology induced by annealing reflect heterogeneities, i.e., differences in molecular order within these crystals. However, so far annealing did not reveal any evident spatial correlations of these heterogeneities. No relation to the initial growth conditions and to the conditions of annealing could be established.

One reason for not observing correlated patterns induced by annealing may be attributed to the typically small differences in degree of order within a single crystal. Thus, to uncover heterogeneities, ${ }^{\mathbf{4 8 , 4 9}}$ differences in thermal stability have to be amplified first. Here, we have chosen a lengthy series of annealing steps which started at low temperatures and slowly moved to higher temperatures. Annealing has to remove sequentially, and with high accuracy, crystalline parts which have an only slightly lower thermal stability than more perfect ones. Upon proper annealing, less stable regions will melt. Simultaneously, the remaining regions will become even more stable, e.g., thicker. Consequently, the finally surviving regions 
reflect, to a large extent, the more stable crystalline parts formed already during crystal growth. By applying suitable annealing sequences, we attempted to unveil the less stable parts of a polymer crystal and aim to answer the following question: are heterogeneities within facetted lamellar single crystals distributed homogeneously or are they arranged according to some pattern?

\section{Experimental}

As a model system for answering these general questions we have chosen an archetypical crystallisable polymer: polyethylene. ${ }^{50,51}$ The here reported phenomenon was first revealed and studied in detail for a partially deuterated sample of low polydispersity index (PDI). To demonstrate the generality of the phenomenon we verified that other PE-samples, including commercial products with high PDI, also exhibited analogous morphological changes induced by appropriate annealing procedures. However, the changes were more accentuated and more uniform for polymers with a narrow molecular weight distribution.

As shown in Table 1, we studied four high molecular weight polyethylene samples, including two homopolymers of protonated polyethylene (PE), a deuterated PE ( $\mathrm{dPE}$ ) and a diblock copolymer of hydrogenated and deuterated polyethylene (hPE$b$-dPE) of different molecular weights. ${ }^{52}$ For all these polymers, single crystals were prepared by a self-seeding method, ${ }^{53}$ from dilute solutions at appropriate crystallization temperatures $\left(T_{\mathrm{c}}\right)$. The polymers were dissolved in $p$-xylene at rather low concentrations of $0.001 \mathrm{wt} \%$ or $0.0001 \mathrm{wt} \%$ by heating the solution ( $c a$. $1 \mathrm{ml}$ in a closed glass vial) first to $130{ }^{\circ} \mathrm{C}$ for $30 \mathrm{~min}$, i.e., well above the nominal dissolution temperature of $c a .100^{\circ} \mathrm{C}$. This so homogenized polymer solution was then rapidly crystallized and aged for 2 hours at $70{ }^{\circ} \mathrm{C}$ in a thermostated bath filled with silicone oil. The solution was subsequently heated to the respective self-seeding temperature $T_{\mathrm{s}}$, where it was kept for 10 minutes. For growing single crystals, the samples were subsequently quickly transferred to another thermostated bath at a pre-set crystallization temperature $T_{\mathrm{c}}$. Drops of such solutions containing suspended PE single crystals were then deposited onto a silicon wafer, an often used substrate. ${ }^{47,54-57}$ After deposition, the solvent was allowed to evaporate completely in vacuum at $25{ }^{\circ} \mathrm{C}$ for 12 hours.

\section{AFM Measurements and annealing of single crystals}

Characterization of the morphology and thermal behaviour of the single crystals was performed by atomic force microscopy (AFM, JPK Instruments, Germany). The microscope was equipped with a high-temperature heating stage accessory, controlling the temperature of the sample, allowing to perform in situ experiments at elevated temperatures. Fig. 1a illustrates a typical temperature protocol used in this study for the in situ AFM experiments. By conducting in situ AFM measurements during annealing of the samples, it was possible to observe, in addition to changes in morphology at the chosen annealing temperature, also changes in the phase-signal of the tappingmode AFM. This phase-signal reflects viscoelastic properties of the sample and thus allowed to distinguish between crystalline and molten regions. However, the relatively high annealing temperatures caused stickiness between the AFM-tip and the molten polymers and made measurements more complex. In addition, due to the required scanning velocities, it was often difficult to obtain high-resolution in situ images with a low noise level.

Thus, some high-resolution AFM images of the morphology evolution after annealing at increasing temperature $\left(T_{\mathrm{a}}\right)$ and for prolonged times were performed ex situ at room temperature. For ex situ experiments, the single crystals were annealed first on a Linkam THMS 600 hot stage (Linkam Scientific Instruments, Tadworth, UK) under nitrogen atmosphere at a desired temperature for a chosen time (mostly 20 minutes). The sample was subsequently cooled to room temperature and investigated by AFM. The sample was further annealed on the Linkam hot stage at a slightly higher temperature and re-examined by AFM. This procedure was repeated several times. However, at room
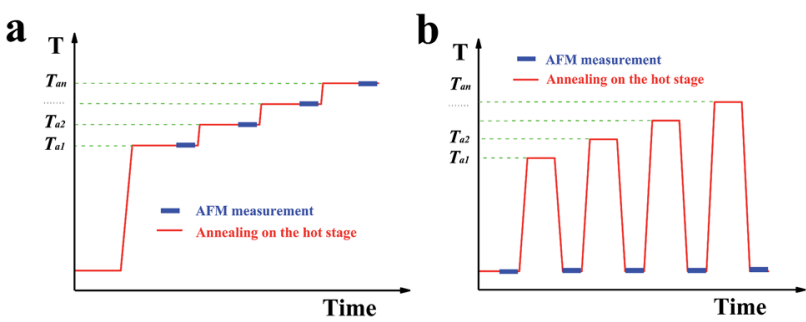

Fig. 1 Experimental protocol employed for the annealing experiments. (a) In situ, (b) ex situ.

Table 1 Characteristics of PE- $b-\mathrm{dPE}, \mathrm{dPE}$ and PE samples and preparation conditions of solution grown single crystals

\begin{tabular}{llcccc}
\hline Code & Material & $M_{\mathrm{w}}\left[\mathrm{g} \mathrm{mol}^{-1}\right]$ & PDI & $\begin{array}{c}T_{\mathrm{s}} \text { (self-seeding } \\
\text { temperature), }\left[{ }^{\circ} \mathrm{C}\right]\end{array}$ & $\begin{array}{l}\text { Crystallization } \\
\text { concentration, }[\mathrm{wt} \%]\end{array}$ \\
\hline PE1 & PE- $b$-deuterated PE & $3.8 \times 10^{6}$ & 1.23 & 105 & 0.0001 \\
PE2 & Deuterated PE & $5.76 \times 10^{5}$ & 1.08 & 100 & 0.001 \\
PE3 & PE & $3.5 \times 10^{6}$ & 7.5 & 106 & 0.0001 \\
PE4 & PE & $7.5 \times 10^{5}$ & 7.5 & 100 & 0.001
\end{tabular}

${ }^{a} 29 \mathrm{~mol} \%$ ethylene-d4 (determined by IR spectroscopy). ${ }^{b}$ The temperature control program for DSC was as follows: (a) heat the as-received polymer bulk sample from room temperature to $200^{\circ} \mathrm{C}$ at a rate of $10^{\circ} \mathrm{C} \mathrm{min}^{-1}$. (b) Keep the polymer melt by holding the temperature at $200{ }^{\circ} \mathrm{C}$ for $5 \mathrm{~min}$. (c) $\mathrm{Cool}$ at a rate of $10^{\circ} \mathrm{C} \mathrm{m^{-1 }}$ down to $-50{ }^{\circ} \mathrm{C}$. (d) Heat the polymer sample from room temperature to $200{ }^{\circ} \mathrm{C}$ at a rate of $10^{\circ} \mathrm{C}$ min ${ }^{-1}$. 
temperature the molten polymers re-crystallized and the AFM phase-signal was not able to distinguish them from the crystalline regions existing at elevated $T_{\mathrm{a}}$. Thus, after a temperature protocol as the one shown in Fig. $1 \mathrm{~b}$ including a quench to room temperature, AFM measurements could only visualize the morphology obtained after the annealing process but could not indicate the amount of molten polymers and their distribution within the single crystal.

\section{Results and discussion}

In Fig. 2, we show a sequence of in situ AFM height images of a truncated lozenge-shaped polyethylene single crystal of PE1, taken after different annealing steps. At each temperature, the sample was kept for $20 \mathrm{~min}$, followed by a temperature increase of a maximum of a few degrees (see also Fig. 1a). Up to an annealing temperature $\left(T_{\mathrm{a}}\right)$ of $c a .122^{\circ} \mathrm{C}$, the crystal morphology almost did not change. Only the crystal periphery became periodically modulated. Notches, bounded by a thickened rim, appeared along the edges of the crystal. These localized changes reflect modulations of stability favoured by the higher mobility of the polymer chains located at the edges of the crystals, i.e., the most unstable parts of crystal. There, reorganization of thermodynamic meta-stable states towards more stable states occurred first.

Upon annealing at $T_{\mathrm{a}}>122^{\circ} \mathrm{C}$, thickened parts became more prominent and grew from the periphery of the crystal in the direction towards the interior of the crystal. The resulting branches progressively carved regularly spaced valleys into the single crystal. Eventually, the branches reached the centre of the crystal, i.e. the initial nucleation site. When heating slightly above $130{ }^{\circ} \mathrm{C}$, valleys were refilled by molten polymers. However, the memory of the branched patterns still existed as the branches re-appeared upon cooling (see also Fig. 3). Only after heating above $c a .135{ }^{\circ} \mathrm{C}$, all memory of a crystalline
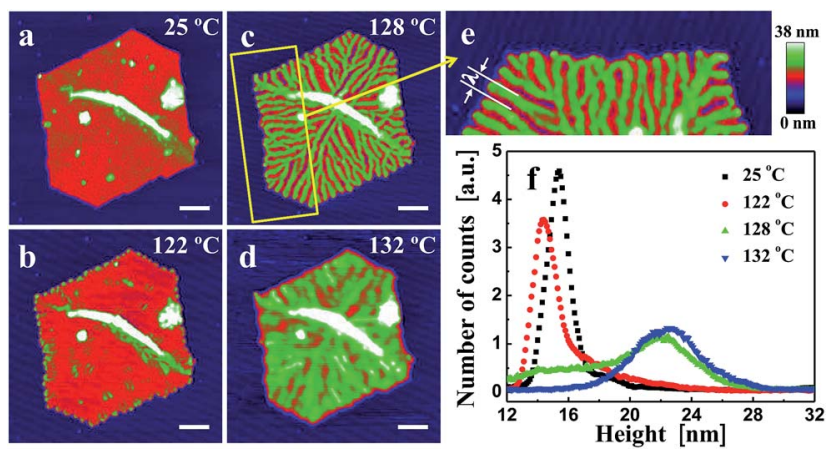

Fig. 2 Morphological changes in a single crystal of polyethylene, induced by annealing at increasing temperatures. (a) PE1 single crystal obtained by isothermal growth [(crystallization temperature $T_{c}$, crystallization time $\left.\left.t_{\mathrm{c}}\right)=\left(83.5^{\circ} \mathrm{C}, 60 \mathrm{~min}\right)\right]$ (see Experimental section). Height images were taken in situ during annealing at temperatures $\left(T_{\mathrm{a}}\right)$ increasing stepwise from $25{ }^{\circ} \mathrm{C}$ to $138{ }^{\circ} \mathrm{C}$ with a constant annealing time $\left(t_{\mathrm{a}}\right)=20 \mathrm{~min}$ per step. $T_{\mathrm{a}}=$ (b) $122^{\circ} \mathrm{C}$, (c) + (e) $128^{\circ} \mathrm{C}$, (d) $132^{\circ} \mathrm{C}$. (f) Height histogram of the PE1 single crystal after annealing at various $T_{a}$. The size of the scale bar is $500 \mathrm{~nm}$. $\lambda$ is the periodic distance between branches.

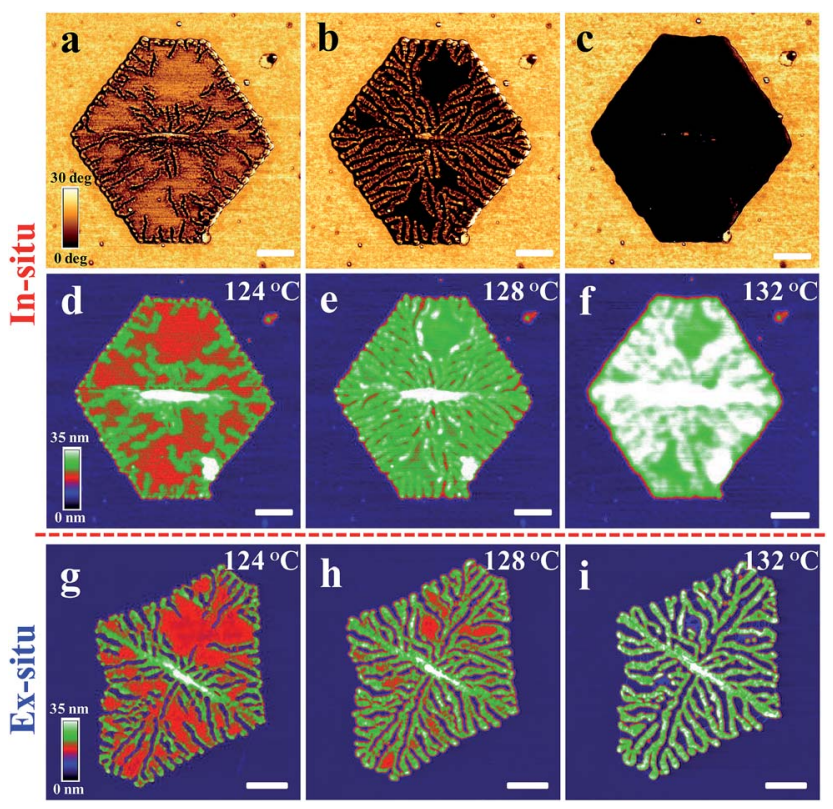

Fig. 3 (a)-(f) In situ annealing. A PE1 single crystal obtained by isothermal growth $\left[\left(T_{\mathrm{c}}, t_{\mathrm{c}}\right)=\left(83.5^{\circ} \mathrm{C}, 60 \mathrm{~min}\right)\right]$. Phase images $(\mathrm{a})-(\mathrm{c})$ and corresponding height images (d)-(f) were taken in situ during annealing at various temperatures $T_{a}$, increasing stepwise from $25^{\circ} \mathrm{C}$ to $132{ }^{\circ} \mathrm{C}$. (g)-(i) Re-crystallization of branched morphology. A different PE1 single crystal obtained by isothermal growth $\left[\left(T_{\mathrm{c}}, t_{\mathrm{c}}\right)=\right.$ $\left.\left(82^{\circ} \mathrm{C}, 20 \mathrm{~min}\right)\right]$. Height images were taken ex situ at room temperature after annealing at various temperatures, increasing stepwise from $25^{\circ} \mathrm{C}$ to $132^{\circ} \mathrm{C}$ for a constant annealing time $t_{\mathrm{a}}$ of $20 \mathrm{~min}$ at each step. The size of the scale bar is always $500 \mathrm{~nm}$.

pattern was lost. It is worth noting that annealing the crystal by jumping right away to temperatures above $c a .130{ }^{\circ} \mathrm{C}$ caused the formation of "Swiss-cheese"-like patterns rather than branches. Thus, slowly removing less perfect crystalline regions by providing enough time for re-organisation within the crystal seems to be required to generate periodic patterns formed within a single crystal.

In addition to identifying local morphological changes, we also determined the mean height of the crystal, recorded during annealing. These mean values allowed a direct comparison with results frequently obtained via averaging techniques like X-ray scattering. ${ }^{34,47}$ As shown in the histogram of Fig. 2f, taken from the recorded AFM images, a sequence of stages can be identified, consistent with previous observations. ${ }^{21}$ For the early stages (low $T_{\mathrm{a}}$ and/or short annealing times $\left(t_{\mathrm{a}}\right)$ ), the mean height of the crystal (its lamellar thickness $\left(l_{\mathrm{d}}\right)$ ) did not change much. Nonetheless, even at such early stages, the morphology already started to change at the crystal periphery. At progressively higher $T_{\mathrm{a}}$, or after prolonged annealing, a stage of local melting and significant reorganization followed (Fig. 2c and d), causing a shoulder to appear at higher thickness values and evolving into a peak in the height histogram. With increasing $T_{\mathrm{a}}$, this new peak, which is typically attributed to lamellar thickening, ${ }^{29,31,58,59}$ slowly shifted to higher values of $l_{\mathrm{d}}$. In combination with the direct space observation by AFM, we can conclude that the lamellar thickening process was accompanied 
by the formation of a regular pattern within the single crystal. For $T_{\mathrm{a}}>130{ }^{\circ} \mathrm{C}$, the height distribution became rather broad, related to the simultaneous melting of large parts of the crystal and thickening of the remaining parts, the branches.

Using the phase-signal of tapping mode AFM, it is possible to visualize differences in viscoelastic properties within an annealed single crystal. Under the imaging conditions used here, the contrast visible in the phase images reflects crystalline (light colours) and molten (dark colours) areas. As can be seen in Fig. 3a, the AFM phase images indicated that in the course of the appearance of the branches, they carved regularly spaced valleys into the single crystal which were partially filled by molten polymers as indicated by the change in the phase signal (the dark colour of the phase signal is indicating molten polymers).

The short waiting time of $10 \mathrm{~min}$ at $T_{\mathrm{a}}=124{ }^{\circ} \mathrm{C}$ did not allow for the formation of branched structures within the whole crystal. After raising the temperature to $128{ }^{\circ} \mathrm{C}$, only the thickened parts, i.e. the parts forming the branched morphology, exhibited a solid-like response in the AFM phase-signal. At even higher temperatures, such as $132{ }^{\circ} \mathrm{C}$ (Fig. 3c), the branched structure seemed to disappear. Under the chosen imaging conditions, it was not visible anymore in the AFM phase-signal. However, when increasing the tapping force, ${ }^{\mathbf{6 0 , 6 1}}$ it became clear that branches still existed but were "hidden" under a layer of molten polymers. In addition, upon quenching to room temperature, the branched structure became clearly visible (compare Fig. 3f and i).

Upon cooling, all molten polymers re-attached to the remaining branches, making them visible again in the AFM topography images. A series of high resolution AFM high images of PE1 single crystals were taken at room temperature after annealing at various $T_{\mathrm{a}}$ (see Fig. $3 \mathrm{~g}-\mathrm{i}$ ). When annealing at temperatures lower than $128^{\circ} \mathrm{C}$, the morphological evolution of the annealing-induced branched pattern was obviously very similar to what was demonstrated in the above in situ AFM images (compare Fig. $2 \mathrm{~b}$ and $\mathrm{c}$ and $3 \mathrm{~b}$ and e). Crack-like structures could be seen both in the central region and at the crystal edges after annealing at $128{ }^{\circ} \mathrm{C}$. As shown in the AFM height image (Fig. 3h), the cracks formed a branched pattern. In addition, the lamellar thickness within such single crystals increased upon annealing.

Upon quenching the sample to room temperature, recrystallisation of polymers from the partially molten state in between the branches contributed to the morphological changes. This became particularly visible for annealing temperatures above $128{ }^{\circ} \mathrm{C}$. It can be deduced by comparison of Fig. 3d-f with Fig. 3g-i that re-crystallisation of the molten polymers was guided by the crystalline branched pattern.

Besides varying $T_{\mathrm{a}}$, we also varied $t_{\mathrm{a}}$ while keeping $T_{\mathrm{a}}$ constant. For example, at $T_{\mathrm{a}}=125{ }^{\circ} \mathrm{C}$, the morphological evolution of one solution-grown faceted crystal is shown in Fig. 4a. Already after $t_{\mathrm{a}}=2 \mathrm{~min}$, numerous notches formed along the crystal edges. With increasing $t_{\mathrm{a}}$, these notches penetrated further towards the centre of the crystal. Elongated branches formed in each sector of the initial crystal, all of them pointing preferentially towards the centre (i.e. the nucleation
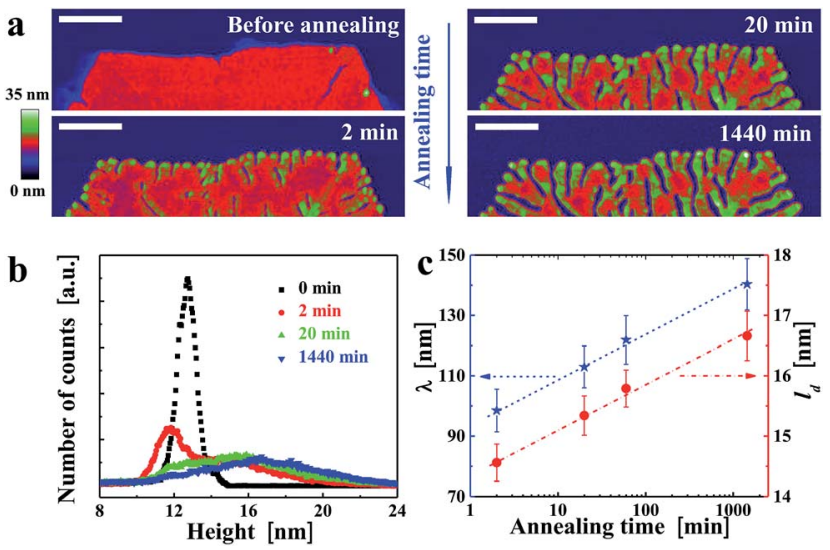

Fig. 4 Temporal evolution of morphological changes induced by annealing. (a) Ex situ height images of a PE1 single crystal (see Experimental section), obtained by isothermal growth at $\left(T_{\mathrm{c}}, t_{\mathrm{c}}\right)=$ $\left(82{ }^{\circ} \mathrm{C}, 20 \mathrm{~min}\right)$, taken after annealing at $125^{\circ} \mathrm{C}$ for various annealing times $t_{a}$, indicated in the figure. Size of the scale bar is $500 \mathrm{~nm}$. (b) Height histograms obtained from the AFM height images in (a), after background subtraction. (c) Evolution of period of the branches $(\lambda$, stars) as a function of annealing time for the measurements shown in (a), compared with the mean thickness $\left(l_{d}\right.$, circles) of the lamellar crystal.

site) of the crystal. As shown in the height histogram of Fig. 4b, a second broad peak emerged at the expense of the initial peak. The comparison of Fig. 2 and 4 reveals a kind of time-temperature superposition. Interestingly, the value of the periodic spacing $(\lambda)$ of the branches increased with $t_{\mathrm{a}}$, reflected by a decrease in number of branches per unit length. This evolution of $\lambda\left(t_{\mathrm{a}}\right)$ followed the same trend as the mean crystal thickness $\left(l_{\mathrm{d}}\right)$ (Fig. 4c), consistent with previous scattering experiments ${ }^{34,36,47}$ which averaged over a large number of crystalline domains. Both, $\lambda$ and $l_{\mathrm{d}}$ increased approximately with the logarithm of $t_{\mathrm{a}}$.

In order to demonstrate the generality of our approach, we have repeated analogous experiments for a variety of PE molecules of high molecular weight, including commercial products (see Experimental section). For all samples, we grew single crystals having the shape of a truncated lozenge. Applying similar annealing procedures, we could generate analogously
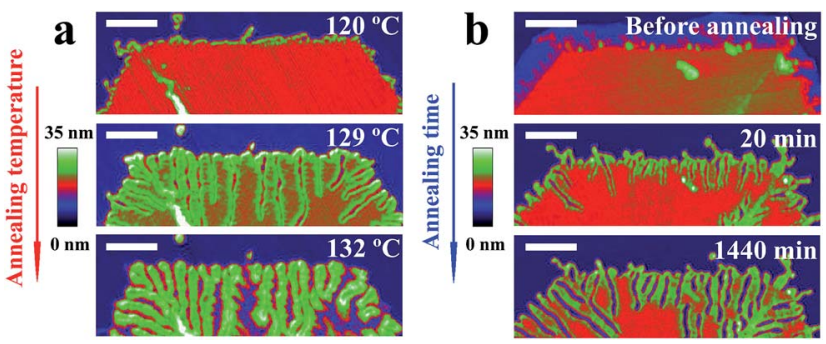

Fig. 5 Confirming the generality of the annealing induced patterns. Series of AFM height images of a single crystal of PE3 recorded after annealing performed at (a) various $T_{\mathrm{a}}$ with $t_{\mathrm{a}}=20 \mathrm{~min}$ and (b) $T_{\mathrm{a}}=$ $127^{\circ} \mathrm{C}$ for various $t_{\mathrm{a}}$. PE3 single crystals were obtained by isothermal growth at $\left(T_{c}, t_{c}\right)=\left(85^{\circ} \mathrm{C}, 90 \mathrm{~min}\right)$. The size of the scale bar is $500 \mathrm{~nm}$. 
branched patterns for all studied samples. As shown in Fig. 5a for a constant annealing time of 20 minutes, $\lambda$ and the length of the branches increased with $T_{\mathrm{a}}$. Keeping $T_{\mathrm{a}}$ constant (Fig. $5 \mathrm{~b}$ ) and varying $t_{\mathrm{a}}$, a similar increase of $\lambda$ was observed.

The initial lamellar thickness $\left(l_{\mathrm{d} 0}\right)$ depends on the growth rate, which, in turn, can be controlled by crystallization temperature $T_{\mathrm{c} \cdot}{ }^{35,62}$ In addition, the thickness $\left(l_{\mathrm{d}}\right)$ of a crystalline lamella can vary during growth in the regions behind the growth front or during post-growth annealing stages. In Fig. 6, we demonstrate that $\lambda$ also depends on $T_{\mathrm{c}}$. This suggests that a relation between $\lambda$ and $l_{\mathrm{d} 0}$ (or $l_{\mathrm{d}}$ ) exists.

As has been shown previously, ${ }^{34,58}$ lamellar thickening induced by annealing is a complex process involving (1) a molecular diffusion process of the detached/molten molecules to more stable, thicker crystalline regions, (2) attachment and incorporation of molecules into these regions, followed by (3) further improvement of stability by removing even more folds and disappearance of less stable regions. Consequently, as shown in Fig. 2-6, annealing temperature and time have a crucial influence on the evolution of morphology and lamellar thickness $\left(l_{\mathrm{d}}\right)$ during/after growth. The rate of such annealinginduced changes depended on the initial degree of order and the morphology of the single crystal, mainly determined by the crystallization temperature.

To shed some light on the origin of annealing-induced branched patterns, we searched for relations between the conditions under which the faceted polymer single crystals were grown and the periodic patterns observed after annealing. For various annealing procedures and crystallization conditions, we analysed a series of single crystals and compared the evolution of $\lambda$ with the accompanying changes in the parameters $l_{\mathrm{d} 0}$ (see Fig. 7a) or $l_{\mathrm{d}}$ (see Fig. 7a). The results are summarized in Fig. 7, from which we can draw the following conclusions. $\lambda$ was found to be much smaller than the size of the faceted crystals and only about ten times larger than $l_{\mathrm{d}}$. As shown in Fig. 4, for constant $T_{\mathrm{a}}, \lambda$ increased approximately with $\log \left(t_{\mathrm{a}}\right)$. Because $l_{\mathrm{d}}$ also increased with $\log \left(t_{\mathrm{a}}\right)$, a clear relation between $\lambda$ and $l_{\mathrm{d}}$ was found. Single crystals prepared at increasing $T_{\mathrm{c}}$ showed an increase in $l_{\mathrm{d} 0}$. As shown in Fig. $7 \mathrm{~b}$ for annealing times increasing with $T_{\mathrm{c}}, \lambda$ also increased with $T_{\mathrm{c}}$, giving rise to an

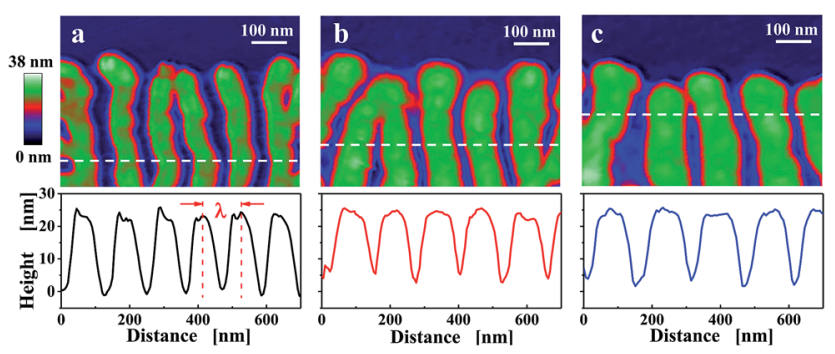

Fig. 6 Dependence of the width of the branches on crystallization temperature of the initial crystal. Tapping mode AFM height images of representative regions close to the edge of truncated-lozenge crystals. Measurements were performed at room temperature after annealing of a PE1 single crystal at $132{ }^{\circ} \mathrm{C}$ for $20 \mathrm{~min}$. Crystals were grown isothermally at $T_{\mathrm{c}}$ for time $t_{\mathrm{c}}:\left(T_{\mathrm{c}}, t_{\mathrm{c}}\right)=(\mathrm{a})\left(82{ }^{\circ} \mathrm{C}, 20 \mathrm{~min}\right),(\mathrm{b})$ (83.5 $\left.{ }^{\circ} \mathrm{C}, 60 \mathrm{~min}\right),(\mathrm{c})\left(85^{\circ} \mathrm{C}, 120 \mathrm{~min}\right)$.
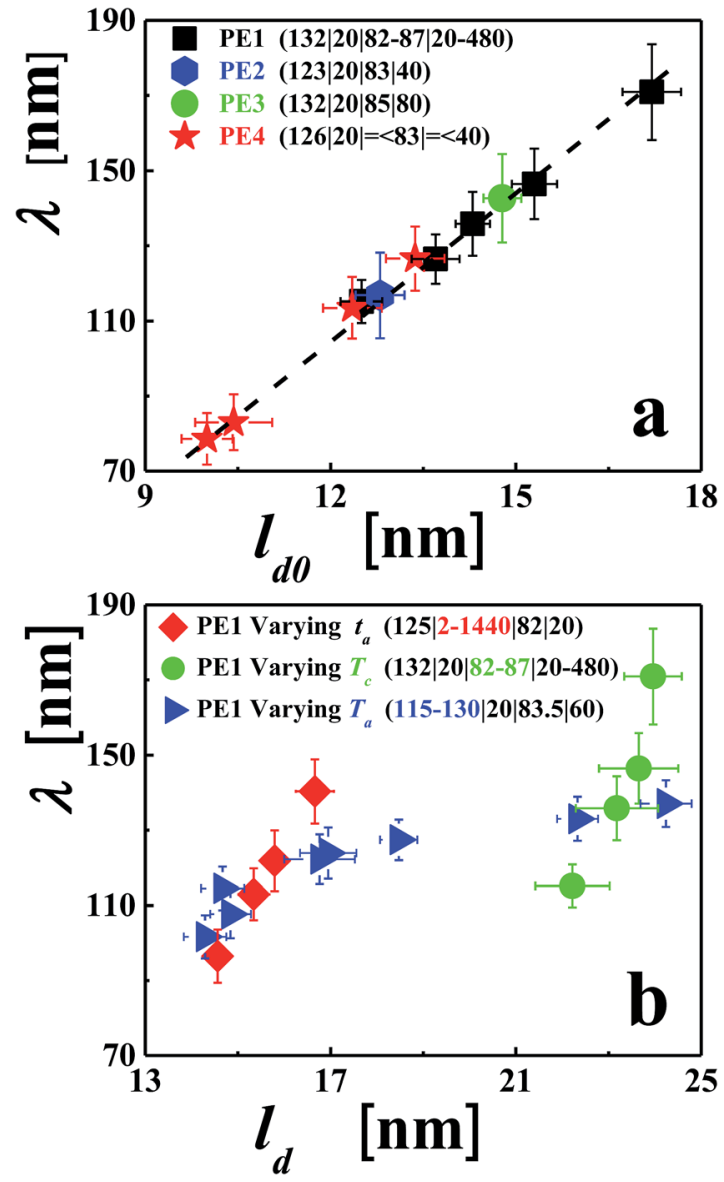

Fig. 7 Correlating the annealing-induced patterns, characterized by the length-scale $(\lambda)$ of the rather periodic branches, with parameters characterizing growth and annealing processes. (a) The generality of the phenomenon is demonstrated through results from four high molecular weight polyethylene samples as a function of the initial crystallization conditions characterized via the lamellar thickness $\left(l_{\mathrm{do}}\right)$ of the not yet annealed crystals, measured directly after growth. For a fixed annealing time $\left(t_{\mathrm{a}}\right)$ of $20 \mathrm{~min}$, the annealing temperature $\left(T_{\mathrm{a}}\right)$ was adjusted to result in well-developed branched patterns. The crystallization temperature $\left(T_{c}\right)$ was varied to allow for crystals having varying values of $l_{\mathrm{do}}$. The crystallization time $\left(t_{\mathrm{c}}\right)$ was varied in order to have crystals of similar lateral size. (b) Comparison of the influence of various annealing procedures, characterized via the annealinginduced changes of lamellar thickness $\left(l_{d}\right)$ and the changes of $\lambda$. All crystals were similar in lateral size, obtained by adjusting $t_{\mathrm{c}}$. Only one parameter (either $t_{a}, T_{c}$ or $T_{a}$, respectively) was varied for each of the three data sets. Annealing and crystallization conditions are represented as: $\left(T_{\mathrm{a}}\left|t_{\mathrm{a}}\right| T_{\mathrm{c}} \mid t_{\mathrm{c}}\right)$.

approximately linear relation between $\lambda$ and $l_{\mathrm{d} 0}$. A more complex behaviour was found when keeping $t_{\mathrm{a}}$ constant (20 minutes) and varying $T_{\mathrm{a}}$ (from 115 to $130{ }^{\circ} \mathrm{C}$ ). At low $T_{\mathrm{a}}, \lambda$ increased rapidly with $l_{\mathrm{d}}$. But at high $T_{\mathrm{a}}, \lambda$ increased only slowly with $l_{\mathrm{d}}$. At low annealing temperatures (from $c a$. 115 to $120{ }^{\circ} \mathrm{C}$ ), changes in morphology could only be observed for crystals grown at low $T_{\mathrm{c}}$. At such conditions, $\lambda$ was found to be small, i.e., the distances between branches were short, allowing for relatively efficient transport of polymer chains between branches. Thus, a coarsening of $\lambda$ was observed even for short annealing 
times. For thicker lamellar crystals, higher temperatures and longer times were required to allow for the annealing-induced changes in morphology to become visible.

\section{Conclusions}

Using solution grown polymer single crystals of polyethylene, one of the simplest and most widely studied polymers, we have been able to change the morphology of faceted crystals by annealing. Under the here applied low-temperature and longlasting annealing conditions, we were able to unveil a rather regularly branched pattern within a polymer single crystal which we tentatively relate to variations in the degree of thermal stability. Upon annealing, the less stable regions, characterized by a lower melting temperature, were redistributed between the more stable regions. The branches, which emerged after annealing, all had similar width and were preferentially oriented towards the centre, the initial nucleation site. Like the thickness of the lamellar crystal, the observed period of the branches depended on the crystallization conditions of the starting crystals but also on the conditions of subsequent annealing. Although within experimental error no regions of different lamellar thickness could be identified within as-grown single crystals, we speculate that such regions of differing degrees of thermal stability existed. These observed annealinginduced morphological changes from a faceted to a branched pattern within polymer single crystals may provide an instructive approach for studying differences in organization and thermal stability created within polymer single crystals in the course of growth.

\section{Acknowledgements}

The authors would also like to thank Gert Strobl, Wenbing $\mathrm{Hu}$, Liangbin Li, Jun Xu, and Murugappan Muthukumar for fruitful discussions. We also would like to acknowledge financial support from the Sino-German Center for Research Promotion and the German Science Foundation. The authors are grateful to the National Science Foundation of China (no. 11172272 and 11372284) and to the China Scholarship Council (CSC) for a grant to BZ and HZ. M.C.B thanks the Fonds der Chemischen Industrie for a Chemiefonds scholarship. The authors thank Lars Bolk for GPC and DSC measurements and Chemtura for the kind donation of MAO solution.

\section{References}

1 T. Haxhimali, A. Karma, F. Gonzales and M. Rappaz, Nat. Mater., 2006, 5, 660-664.

2 G. R. Strobl, The physics of polymers, Springer, 1997.

3 E. Ben-Jacob and P. Garik, Nature, 1990, 343, 523-530.

4 R. Trivedi, S. Liu and S. Williams, Nat. Mater., 2002, 1, 157159.

5 G. Reiter and G. R. Strobl, Progress in understanding of polymer crystallization, Springer, 2007.

6 X. Jiang, X. Liu, Q. Liao, X. Wang, D.-D. Yan, H. Huo, L. Li and J.-J. Zhou, Soft Matter, 2014, 10, 3238-3244.
7 A. Keller, Polymer, 1962, 3, 393-421.

8 G. Tegze, G. I. Tóth and L. Gránásy, Phys. Rev. Lett., 2011, 106, 195502.

9 L. Gránásy, T. Pusztai, T. Börzsönyi, J. A. Warren and J. F. Douglas, Nat. Mater., 2004, 3, 645-650.

10 P. Ball, Nature, 2011, 480, 455.

11 X. Liu, Y. Zhang, D. K. Goswami, J. S. Okasinski, K. Salaita, P. Sun, M. J. Bedzyk and C. A. Mirkin, Science, 2005, 307, 1763-1766.

12 G. Reiter, G. Castelein and J.-U. Sommer, Phys. Rev. Lett., 2001, 86, 5918.

13 K. Rahimi, I. Botiz, N. Stingelin, N. Kayunkid, M. Sommer, F. P. V. Koch, H. Nguyen, O. Coulembier, P. Dubois and M. Brinkmann, Angew. Chem., Int. Ed., 2012, 51, 1113111135.

14 M. Voigt, S. Dorsfeld, A. Volz and M. Sokolowski, Phys. Rev. Lett., 2003, 91, 026103.

15 S. Z. D. Cheng, Nature, 2007, 448, 1006-1007.

16 S. Organ and A. Keller, J. Polym. Sci., Part B: Polym. Phys., 1986, 24, 2319-2335.

17 B. Wunderlich and P. Sullivan, J. Polym. Sci., 1962, 61, 195221.

18 P. H. Geil and D. H. Reneker, J. Polym. Sci., 1961, 51, 569582.

19 K. Kuwabara, H. Kaji, M. Tsuji and F. Horii, Macromolecules, 2000, 33, 7093-7100.

20 Y. Jiang, X.-G. Jin, C. C. Han, L. Li, Y. Wang and C.-M. Chan, Langmuir, 2003, 19, 8010-8018.

21 Y. Kikkawa, H. Abe, T. Iwata, Y. Inoue and Y. Doi, Biomacromolecules, 2001, 2, 940-945.

22 B. Wunderlich and G. Czornyj, Macromolecules, 1977, 10, 906-913.

23 N. Dubreuil, S. Hocquet, M. Dosière and D. A. Ivanov, Macromolecules, 2004, 37, 1-5.

$24 \mathrm{~J}$. Loos and M. Tian, Polymer, 2006, 47, 5574-5581.

25 M. Fujita and Y. Doi, Biomacromolecules, 2003, 4, 1301-1307.

26 T. Liu, J. Petermann, C. He, Z. Liu and T.-S. Chung, Macromolecules, 2001, 34, 4305-4307.

27 T. Liu, W. C. Tjiu and J. Petermann, J. Cryst. Growth, 2002, 243, 218-223.

28 J. Xu, Y. Ma, W. Hu, M. Rehahn and G. Reiter, Nat. Mater., 2009, 8, 348-353.

29 N. Basu, A. Osichow, S. Mecking and G. Reiter, Eur. Phys. J. E: Soft Matter Biol. Phys., 2012, 35, 1-12.

30 J. Nakamura, M. Tsuji, A. Nakayama and A. Kawaguchi, Macromolecules, 2008, 41, 1358-1363.

31 M. Wang, H. Gao, L. Zha, E.-Q. Chen and W. Hu, Macromolecules, 2012, 46, 164-171.

32 F. Zhang, G. G. Baralia, B. Nysten and A. M. Jonas, Macromolecules, 2011, 44, 7752-7757.

33 B. Zhang, J. Chen, M. C. Baier, S. Mecking, R. Reiter, R. Mülhaupt and G. Reiter, Macromol. Rapid Commun., 2015, 36, 181-189.

34 Y.-X. Liu, J.-F. Li, D.-S. Zhu, E.-Q. Chen and H.-D. Zhang, Macromolecules, 2009, 42, 2886-2890.

35 G. Reiter, Chem. Soc. Rev., 2014, 43, 2055-2065. 
36 C. N. Rochette, S. Rosenfeldt, K. Henzler, F. Polzer, M. Ballauff, Q. Tong, S. Mecking, M. Drechsler, T. Narayanan and L. Harnau, Macromolecules, 2011, 44, 4845-4851.

37 B. Zhang, J. Chen, J. Cui, H. Zhang, F. Ji, G. Zheng, B. Heck, G. N. Reiter and C. Shen, Macromolecules, 2012, 45, 89338937.

38 W. O. Statton and P. H. Geil, J. Appl. Polym. Sci., 1960, 3, 357361.

39 P. Dreyfus and A. Keller, J. Polym. Sci., Part B: Polym. Phys., 1970, 8, 253-258.

40 P. H. Geil, Polymer Single Crystals, Interscience Publishers, New York, 1963.

41 A. Peterlin, J. Polym. Sci., Part B: Polym. Phys., 1963, 1, 279284.

42 R. J. Roe, C. Gieniewski and R. G. Vadimsky, J. Polym. Sci., Polym. Phys. Ed., 1973, 11, 1653-1670.

43 H. E. Bair, R. Salovey and T. W. Huseby, Polymer, 1967, 8, 920.

44 R. I. Gearba, N. Dubreuil, D. V. Anokhin, Y. K. Godovsky, J.-J. Ruan, A. Thierry, B. Lotz and D. A. Ivanov, Macromolecules, 2006, 39, 978-987.

45 X. Wang, J. Zhou, L. Li and C. M. Chan, Macromol. Rapid Commun., 2007, 28, 2001-2006.

46 N. Sanz, J. Hobbs and M. Miles, Langmuir, 2004, 20, 59895997.

47 S. Hocquet, M. Dosiere, A. Thierry, B. Lotz, M. H. J. Koch, N. Dubreuil and D. A. Ivanov, Macromolecules, 2003, 36, 8376-8384.
48 S. Rastogi, D. R. Lippits, G. W. Peters, R. Graf, Y. Yao and H. W. Spiess, Nat. Mater., 2005, 4, 635-641.

49 H. Li, J. Liu, D. Wang and S. Yan, Colloid Polym. Sci., 2003, 281, 973-979.

50 U. W. Gedde and A. Mattozzi, in Long Term Properties of Polyolefins, Springer, 2004, pp. 29-74.

51 D. C. Bassett and A. Keller, Philos. Mag., 1962, 7, 1553-1584.

52 S.-M. Yu and S. Mecking, J. Am. Chem. Soc., 2008, 130, 1320413205.

53 D. Blundell, A. Keller and A. Kovacs, J. Polym. Sci., Part B: Polym. Phys., 1966, 4, 481-486.

54 Y. Ryousho, S. Sasaki, T. Nagamura, A. Takahara and T. Kajiyama, Macromolecules, 2004, 37, 5115-5117.

55 M. Tian and J. Loos, J. Polym. Sci., Part B: Polym. Phys., 2001, 39, 763-770.

56 J. Nakamura and A. Kawaguchi, Macromolecules, 2004, 37, 3725-3734.

57 Y. Wang, M. Rafailovich, J. Sokolov, D. Gersappe, T. Araki, Y. Zou, A. D. L. Kilcoyne, H. Ade, G. Marom and A. Lustiger, Phys. Rev. Lett., 2006, 96, 028303.

58 S. J. Organ, J. K. Hobbs and M. J. Miles, Macromolecules, 2004, 37, 4562-4572.

59 M. I. Abo el Maaty and D. C. Bassett, Polymer, 2005, 46, 86828688.

60 A. Knoll, R. Magerle and G. Krausch, Macromolecules, 2001, 34, 4159-4165.

61 G. Bar, Y. Thomann, R. Brandsch, H.-J. Cantow and M.-H. Whangbo, Langmuir, 1997, 13, 3807-3812.

62 J. D. Hoffman and R. L. Miller, Polymer, 1997, 38, 3151-3212. 